\title{
Tensile properties of PLA/PBAT blends and PLA fibre-reinforced PBAT composite
}

\author{
Eakasit Sritham ${ }^{1, *}$, Phakaimat Phunsombat $^{1}$ and Jedsada Chaishome $^{1}$ \\ ${ }^{1}$ Food Engineering Department, Faculty of Engineering, King Mongkut's Institute of Technology Ladkrabang, Bangkok, Thailand
}

\begin{abstract}
The tensile properties of PLA/PBAT blends, PLA fibre reinforced PBAT composite (PLAF) at room temperature and $-18{ }^{\circ} \mathrm{C}$ were investigated. The concentrations of PLA in the blends were $10 \%, 20 \%$, $30 \%$ and $40 \%$ (by volume). There was an improvement of elastic modulus $(E)$ for PLA/PBAT blends when PLA was $40 \%$. There was no significant difference of ultimate tensile strength (UTS) among the blends. For the same concentration of PLA (40\%) in PLA-PBAT mixture, PLAF exhibited higher values of $E$ and UTS than that of PLA/PBAT blends. Elongation of PLA/PBAT blends rapidly decreased upon the addition of PLA to the blends. The values of $E$ and UTS for PLA/PBAT blends and composite, neat PLA, and PP increased with the decreasing of temperature from room temperature to $-18^{\circ} \mathrm{C}$. The effect of decreasing temperature was not observed on elongation. It was appeared from the results obtained for FTIR and DSC measurements that PLA and PBAT were immiscible, separating into two phases.
\end{abstract}

\section{Introduction}

Non-biodegradable plastics have posed an environment concern worldwide. The short time end-of-life products drastically affect global weather and landfill area hazards. The degree of concern has been raised along with the development in urbanization. [1-8] Accordingly, much of attention from a number of researchers has been devoted to replace synthetic plastics with bioplastics, such as poly(lactic acid) or (PLA), poly(3-hydroxy butyrate) or (PHB), and poly(butyl succinate) or (PBS) [1-5]. These bioplastics are biodegradable in nature.

Among bioplastics, PLA offers the highest tensile strength and being available at considerably low cost. PLA appears to be a high potential candidate to replace polypropylene (PP) - a thermoplastic polymer that has been commonly used in a broad range of applications including food packaging. However, PLA is typically brittle which limits its applications, particularly, at low temperatures. As to provide an alternative to synthetic plastics for eco-friendly food packaging industry, the impact resistance of PLA need to be enhanced $[1,3]$.

Poly(butylene adipate-co-terephthalate) or (PBAT) is biodegradable random copolymer which is flexible. By incorporating with PLA, the PBAT is expected to help improve the flexibility of the polymer blend/composite.

Though preparing PAL(fiber)/PBAT composite could be challenging, some mechanical properties might be positively improved making it suitable for using as food packaging material.

This study was primarily aimed to investigate the tensile properties of PLA/PBAT blends and PLA fiber- reinforced PBAT composite at room temperature and frozen temperature.

\section{Materials and methods}

\subsection{Materials}

PBAT (Ecoflex F Blend 1200) was purchased from BASF Company. PLA (grade 2003D) was purchased from Nature Work Company. PP (grade 1102k) was purchased from Global Connections Company. The polymers, as received, were dried in a hot air oven at $80^{\circ} \mathrm{C}$ for $6 \mathrm{hr}$ before further preparation of experimental treatments.

\subsection{Samples preparation}

The neat polymers were manufactured by compression moulding for $5 \mathrm{~min}$ at $1 \mathrm{MPa}$ and temperatures of $165^{\circ} \mathrm{C}$, $130^{\circ} \mathrm{C}$, and $200^{\circ} \mathrm{C}$ for PLA, PBAT and PP, respectively.

The formulations of PLA/PBAT blends were given in Table 1 . The blends were mixed using an extruder at $165^{\circ} \mathrm{C}$ and $20 \mathrm{rpm}$, and were subjected to compression moulding at $165^{\circ} \mathrm{C}$ and $1 \mathrm{MPa}$ for $5 \mathrm{~min}$.

The treatment PLAF was prepared so that PLA remained in a form of fiber. PLA was first melted using an extruder at $170^{\circ} \mathrm{C}$ and $50 \mathrm{rpm}$. Then PLA fibers were pulled from the extruder to a spinner rotating at a speed of $150 \mathrm{rpm}$. Finally PLA fiber reinforced PBAT composite was manufactured by compression moulding at $130^{\circ} \mathrm{C}$ and $1 \mathrm{MPa}$ for $5 \mathrm{~min}$.

\footnotetext{
Corresponding author: eakasit.sr@kmitl.ac.th
} 
Table 1. Treatment formulations and code name of polymer blend/composite samples.

\begin{tabular}{ccc}
\hline Treatments & $\begin{array}{c}\text { PLA:PBAT ratio } \\
\text { (by volume) }\end{array}$ & Code name \\
\hline 1 & $100: 0$ & PLA \\
2 & $40: 60$ & PLA40 \\
3 & $30: 70$ & PLA30 \\
4 & $20: 80$ & PLA20 \\
5 & $10: 90$ & PLA10 \\
6 & $0: 100$ & PBAT \\
7 & 40 (fiber): 60 & PLAF \\
\hline
\end{tabular}

\subsection{Tensile property measurements}

The measurements for tensile properties at room temperature were performed according to ISO 527:1996 using a computerized tensile testing machine model QC536M1 (COMETECH). A total of five specimens for each treatment were tested at a rate of $200 \mathrm{~mm} / \mathrm{min}$. For the measurements at low temperature, sample specimens were infused in liquid nitrogen for $10 \mathrm{~min}$ before testing. The elastic modulus $(E)$, elongation at break $\left(E_{\mathrm{b}}\right)$ and tensile strength (UTS) were obtained from a stress-strain curve.

\subsection{Fourier transform infrared spectroscopy (FTIR)}

FTIR measurements were carried out at room temperature using the IRPrestige-21 (Shimadzu) spectrometer in attenuated total reflectance (ATR) mode. Experimental control and spectral analyses were made with a Windows based IRsolution software bundled with the spectrometer. Samples were scan in a range of 4000 to $750 \mathrm{~cm}^{-1}, 20$ scans per measurement, with a resolution of $8 \mathrm{~cm}^{-1}$.

\subsection{Differential scanning calorimetry (DSC)}

Thermal property of samples was studied using the differential scanning calorimeter model DSC 204 F1 Phoenix $^{\circledR}$ (NETZSCH, Germany). A 50-mg sample was weighed and tested under nitrogen atmosphere. Samples were subjected to a temperature scan where it was heated from $-50^{\circ} \mathrm{C}$ to $200^{\circ} \mathrm{C}$ and subsequently cooled down to $50^{\circ} \mathrm{C}$, both at the same rates of $10^{\circ} \mathrm{C} / \mathrm{min}$.

\subsection{Statistical analysis}

The experiments were laid out in a completely randomized design (CRD). Three replicates were made. The analysis of variance (ANOVA) was performed on experimental data at a significance level of 0.5. Sample means were compared using the Tukey's test when significant difference $(\mathrm{p}<0.05)$ was found.

\section{Results and discussion}

\subsection{Tensile properties of polymer blends and polymer composite}

Other than neat PBAT and neat PLA, for comparison purpose, PP sample was also tested along with the samples of PLA/PBAT blends and PLA(fiber)/PBAT composite. The results for elastic modulus $(E)$, ultimate tensile strength (UTS), and elongation at break $\left(E_{\mathrm{b}}\right)$ are shown in Figs. 1-3, respectively.

\subsubsection{Elastic modulus}

From Fig.1, it could be clearly observed that the neat PLA exhibited much higher elastic modulus (around 567-974 MPa) than that of the neat PBAT (around 40-50 $\mathrm{MPa}$ ), and even higher than that of PP (around 288-640 $\mathrm{MPa})$. The modulus of neat PBAT, PLA10, PLA20 and PLA30 were not significant different. The improvement of modulus could only be seen when PLA concentration in the blend was increased to $40 \%$ (treatment PLA40). The results indicated poor interfacial adhesion between PBAT and PLA that led to the phase separation of PLA/PBAT blend. Ibrahim et al. reported that addition of more than $70 \%$ of PBAT deteriorated the properties of the PVC/PBAT blends [9].

It could be also seen that PLAF showed a higher modulus (around 213-501 MPa) as compared to that of PLA40. The finding suggests that for the same concentration of PLA in PLA-PBAT mixture, said 40\%, preparing PLA in the form of fiber yields the higher elastic modulus than melting and blending with PBAT-treatment PLA40. The modulus of PLAF was close to that of PP, but statistically significantly lowers.

Statistical analysis indicated that temperature significantly affects elastic modulus of the samples. Lowering the temperature from room temperature down to $-18^{\circ} \mathrm{C}$ caused the increase of elastic. These could be clearly seen in treatments PLA, PLAF and PP.

\subsubsection{Ultimate tensile strength}

It could be seen from Fig. 2. that the obtained values of ultimate tensile (UTS) strength of samples were of similar trend with that of the elastic modulus. PLA exhibited the highest value of ultimate tensile strength (UTS), around 52-67 MPa. The addition of PLA, up to $40 \%$, to PLA/PBAT blends did not affect the UTS. The UTS values of these treatments were in a range of approximately 9 to $14 \mathrm{MPa}$. It was also found that, for the same concentration of PLA in PLA-PBAT mixture, at $40 \%$, preparing PLA in the form of fiber yields the higher UTS value than melting and blending with PBAT-treatment PLA40. The UTS value of PLAF was close to that of PP, but statistically significantly lowers.

On the whole, lowering the temperature from room temperature down to $-18^{\circ} \mathrm{C}$ significantly resulted in the increase of UTS. Like the case of elastic modulus, the 
finding could be clearly seen in treatments PLA, PLAF and PP.

\subsubsection{Elongation at break}

PBAT showed a distinctively high value of elongation at break $\left(E_{\mathrm{b}}\right)$, around $477-458 \%$, as compared to that of PLA (around 8-12\%) and PP (around 7-13\%), indicating its highly flexible nature. The addition of PLA to PLA/PBAT blends gradually degraded the value of $E_{\mathrm{b}}$, the flexibility. With the concentration of PLA in the blends from $30 \%$ upward, $E_{\mathrm{b}}$ dropped to the lowest values for PLA/PBAT mixture in this experiment, approximately $13 \%$ (Fig. 3 ).

In contrast to elastic modulus and the ultimate tensile strength, the decrease of temperature from room temperature to $-18^{\circ} \mathrm{C}$ did not significantly affect the elongation at break.

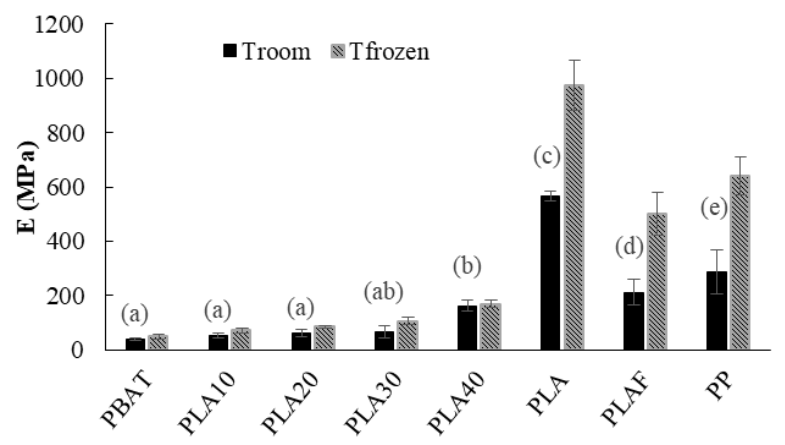

Fig. 1. Elastic modulus $(E)$ of neat PLA, neat PBAT, neat PP, PLA/PBAT blends, and PLA fiber/PBAT composite.

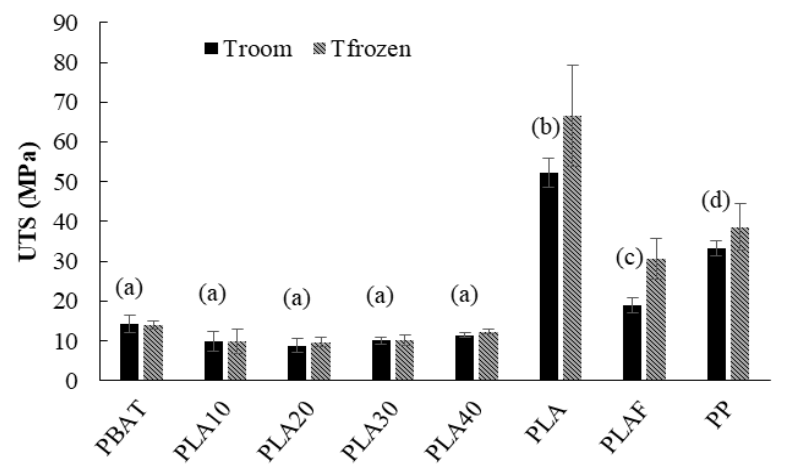

Fig. 2. Ultimate tensile strength (UTS) of of neat PLA, neat PBAT, neat PP, PLA/PBAT blends, and PLA fiber/PBAT composite.

\subsection{FTIR absorption characteristics}

FTIR absorption peaks for the neat PLA, PBAT and PLA/PBAT blends are given in Table 2.

For PLA, the peak at around $752 \mathrm{~cm}^{-1}$ associated with the rocking vibration of $\alpha$-methyl; peak at around $864 \mathrm{~cm}^{-1}$ associated with the ester $\left(\mathrm{O}-\mathrm{CH}-\mathrm{CH}_{3}\right)$; the peak at around $1042 \mathrm{~cm}^{-1}, 1080 \mathrm{~cm}^{-1}$ and $1180 \mathrm{~cm}^{-1}$ associated

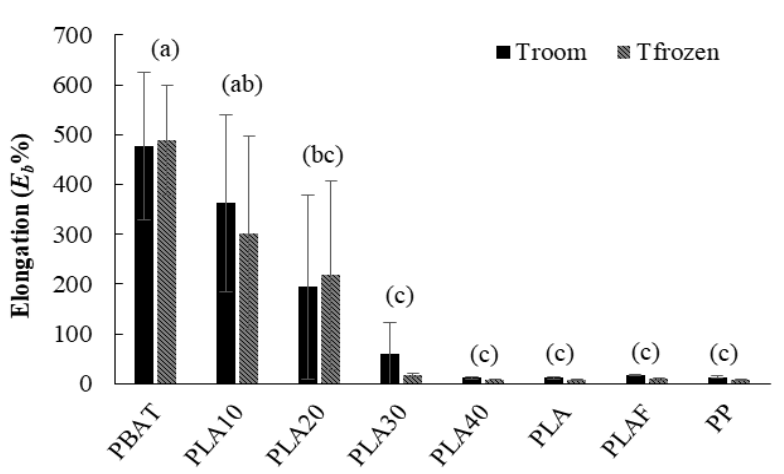

Fig. 3. Elongation at break $\left(E_{\mathrm{b}}\right)$ of of neat PLA, neat PBAT, neat PP, PLA/PBAT blends, and PLA fiber/PBAT composite.

with the stretching vibration of C-O-C; the peak at $1381 \mathrm{~cm}^{-1}$ associated with the $\mathrm{CH}$ symmetric bending vibration; the peak at around $1450 \mathrm{~cm}^{-1}$ associated with the $\mathrm{CH}_{3}$ antisymmetric; the peak at $1748 \mathrm{~cm}^{-1}$ associated with the carbonyl $\mathrm{C}=\mathrm{O}$ stretching vibration; and the symmetric and antisymmetric stretching vibration of $\mathrm{CH}_{3}$ of saturated hydrocarbons were found at $2943 \mathrm{~cm}^{-1}$ and $2997 \mathrm{~cm}^{-1}$, respectively [10,11].

For PBAT, the peak at $725 \mathrm{~cm}^{-1}$ associated with the bending vibration of $\mathrm{CH}$-plane of benzene ring; the symmetric stretching vibration of trans-C-O was found at $937 \mathrm{~cm}^{-1}$; the peak at $1018 \mathrm{~cm}^{-1}$ associated with the bending vibration at the surface of adjacent hydrogen atoms on the phenyl ring; the peak at $1103 \mathrm{~cm}^{-1}$ associated with the left-right symmetric stretching vibration of $\mathrm{C}-\mathrm{O}$; the peak at $1265 \mathrm{~cm}^{-1}$ associated with the $\mathrm{C}-\mathrm{O}$ symmetric stretching vibration; the peak at 1408 $\mathrm{cm}^{-1}$ associated with the trans- $\mathrm{CH}_{2}$-plane bending vibration; the peak at $1504 \mathrm{~cm}^{-1}$ associated with the skeleton vibration of the benzene ring; the peak at 1713 $\mathrm{cm}^{-1}$ associated with the $\mathrm{C}-\mathrm{O}$ stretching vibration; and the peak at $2959 \mathrm{~cm}^{-1}$ associated with the $\mathrm{CH}_{2}$ asymmetric stretching vibration $[10,11]$.

Table 2. FTIR absorption peaks of neat PLA, neat PBAT and PLA/PBAT blends.

\begin{tabular}{cccccc}
\hline \multicolumn{5}{c}{ Wavenumber $\mathbf{( c m}^{-1} \mathbf{)}$} \\
PBAT & PLA & PLA10 & PLA20 & PLA30 & PLA40 \\
\hline 725 & - & 729 & 729 & 729 & 729 \\
- & 752 & - & - & - & - \\
- & 864 & 872 & 872 & 872 & 872 \\
937 & - & 937 & 937 & 937 & 937 \\
1018 & - & 1018 & 1018 & 1018 & 1018 \\
- & 1042 & - & - & - & - \\
- & 1080 & - & - & - & - \\
1103 & - & 1103 & 1103 & 1103 & 1013 \\
- & 1180 & - & - & - & 1180 \\
1265 & - & 1265 & 1265 & 1265 & 1269 \\
- & 1381 & 1389 & 1389 & 1389 & 1389 \\
1408 & - & 1408 & 1408 & 1408 & 1408 \\
- & 1450 & 1458 & 1458 & 1454 & 1454 \\
1504 & - & 1504 & 1504 & 1504 & 1504 \\
1713 & - & 1713 & 1713 & 1713 & 1713 \\
- & 1748 & - & - & - & - \\
- & 2943 & - & - & - & - \\
2959 & - & 2959 & 2959 & 2955 & 2955 \\
- & 2997 & - & - & - & - \\
\hline
\end{tabular}


Absorption spectral of PLA/PBAT blends showed the up-shift of CH-plane of the benzene ring vibration from 725 to $729 \mathrm{~cm}^{-1}$. Ester vibration peak in PLA shifted from 864 to $872 \mathrm{~cm}^{-1}$. Data obtained for PLA40 showed the up-shift of $\mathrm{C}-\mathrm{O}$ symmetric stretching vibration from 1265 to $1269 \mathrm{~cm}^{-1}$, also reported elsewhere [7]. There was however no clear evidence of interaction between PLA and PBAT in the blends.

\subsection{Glass transition and melting temperatures}

DSC thermogram of PLA/PBAT blends generally showed two $T_{\mathrm{g}}$ 's and two $T_{\mathrm{m}}$ 's corresponding to those for PLA and PBAT. The Fig.4 presents the typical thermogram of PLA40 showing the $T_{\mathrm{g}}$ values at $-33.7^{\circ} \mathrm{C}$ and $56^{\circ} \mathrm{C}$, for PBAT and PLA phases, respectively; and the $T_{\mathrm{m}}$ values at $129.9^{\circ} \mathrm{C}$ and $147.9^{\circ} \mathrm{C}$, respectively for PBAT and PLA phases. Given in Table 3 are additional data for $T_{\mathrm{g}}$ and $T_{\mathrm{m}}$ values obtained for PLA/PBAT blends. The results suggested that PLA/PBAT blends were immiscible $[2,4]$.

Table 3. The thermal properties of neat PLA, neat PBAT and PLA/PBAT blends.

\begin{tabular}{ccccc}
\hline Polymers & $\boldsymbol{T}_{\mathbf{g} 1}\left({ }^{\mathbf{0}} \mathbf{C}\right)$ & $\boldsymbol{T}_{\mathbf{g} 2}\left({ }^{\mathbf{0}} \mathbf{C}\right)$ & $\boldsymbol{T}_{\mathbf{m} 1}\left({ }^{\mathbf{}} \mathbf{C}\right)$ & $\boldsymbol{T}_{\mathbf{m} 2}\left({ }^{\circ} \mathbf{C}\right)$ \\
\hline PBAT & -33.8 & - & 122.9 & - \\
PLA10 & -36.2 & 55.3 & 126.3 & 148.6 \\
PLA20 & -34.9 & 55.5 & 128.0 & 148.1 \\
PLA30 & -36.3 & 55.6 & 128.3 & 147.5 \\
PLA40 & -34.0 & 55.7 & 128.6 & 147.6 \\
PLA & - & 56.1 & - & 152.9 \\
\hline
\end{tabular}

However, $T_{\mathrm{m}}$ of PBAT phase in the blends slightly increased with increasing PLA as $T_{\mathrm{g}}$ of PLA phase in the blends were slightly decreased by the increase of PBAT according to the results obtained by Zhao et al. [5], $T_{\mathrm{g}}$ and $T_{\mathrm{m}}$ of PLA were slightly changed by the addition of PBAT. The results accorded to the shifting of the FTIR spectrum.

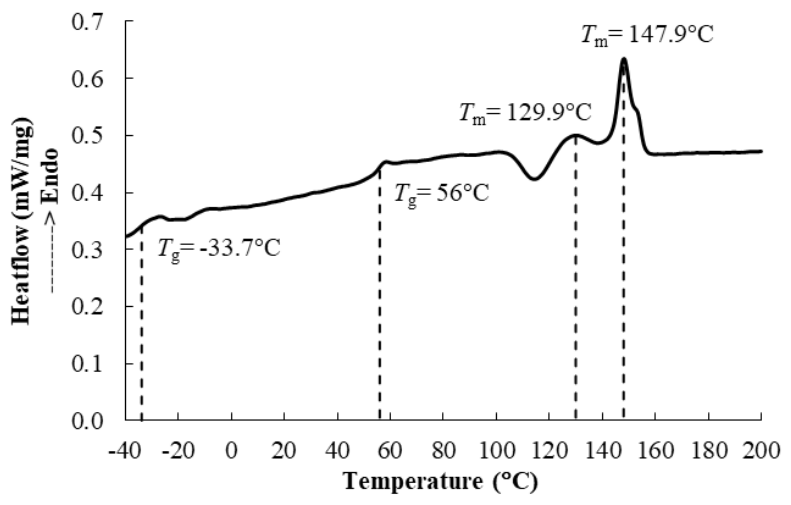

Fig. 4. Typical DSC thermogram of polymer blend sample: treatment PLA40

\section{Conclusions}

Elastic modulus of PLA/PBAT blends could be improved when the concentration of PLA was at least $40 \%$ (by volume). However, the addition of PLA to PLA/PBAT blends from $10 \%$ to $40 \%$ did not affect the ultimate tensile strength. For the same concentration of PLA (40\%) in PLA-PBAT mixture, PLA(fiber)/PBAT composite exhibited the higher elastic modulus and ultimate tensile strength that that of PLA/PBAT blends. Elongation of PLA/PBAT blends rapidly decreased upon the addition of PLA to the blends. The decrease of temperature from room temperature to $-18^{\circ} \mathrm{C}$ allowed elastic modulus and the ultimate tensile strength of PLA/PBAT blends and composite, neat PLA, and PP to increase significantly; but did not affect the elongation. Results from FTIR and DSC measurements suggested that PLA and PBAT were immiscible.

\section{Acknowledgments}

The authors would like to express thanks to the National Research Council of Thailand (NRCT) for its financial support-a graduate research scholarship 2017.

\section{References}

1. W. Jia, R.H. Gong, P.J. Hogg, Compos. Part B: Eng., 62, 104-112 (2014).

2. E. Jalali Dil, P.J. Carreau, and B.D. Favis, Polymer 68: 202-212 (2015).

3. W. Pivsa-Art, A. Chaiyasat, S. Pivsa-Art, H. Yamane, H. Ohara, Energy Procedia 34, 549-554 (2013).

4. T. Yu, Y. Li, Compos. Part A: Appl. S., 58, 24-29 (2014).

5. P. Zhao, W. Liu, Q. Wu, J. Ren, J. Nanomater. 2010, 287082 (2010).

6. J. Chaishome, K.A. Brown, R. Brooks and M.J. Clifford, Advanced Materials Research., 894, 32-36 (2014)

7. J. Chaishome and S. Rattanapaskorn. IOP Conference Series: Materials Science and Engineering., 191, (2017).

8. J. Chaishome and S. Rattanapaskorn, Materials Science Forum., 894, 46-49 (2017).

9. N.A. Ibrahim, N.M. Rahim, W.Z.W. Yunus, J. Sharif, J. Polym. Res. 18(5), 891-896 (2011).

10. Y.X. Weng, Y.J. Jin, Q.Y. Meng, L. Wang, M. Zhang, Y.Z. Wang, Polym. Test. 32(5), 918-926 (2013).

11. M. Xiuyu, W. Yufeng, W. Jianqing, X. Yaning, MATEC Web of Conferences, 88, 02009 (2017). 